\title{
6.4. Residents and Migrants in the Population
}

Kazimierz PETRUSEWICZ

\subsubsection{Concepts Related to Residency and Migration}

The problems of migration and residency have prompted much controversy about the terminology and the essence of this issue. Therefore, I shall start by discussing the concepts and the relevant terminology.

I call a migrant each individual without a home range at a given time. Migration is defined as a movement in certain direction or without direction until settlement or death.

Migration can be divided into micromigration and macromigration, the latter being also simply called migration (Petrusewicz \& Andrzejewski, 1962; Andrzejewski, 1963). Micromigration is defined as movement within the population area. Micromigration (or migration) occurs when an individual or some individuals go beyond the population area, and colonize a new biotope or they immigrate to the area of another population.

A concept related to migration is dispersal. Many authors (e.g. Lidicker, 1975) differentiate between migration and dispersal. They call migration a process in which an individual leaves its population or settles in another population. Thus this is what I call macromigration (or migration). They call dispersal each movement within the population, thus what I call micromigration. They use the term "vagrants" for micromigrants, and call them "homeless travelers". It seems that when I speak about micromigration and migration (macromigration), there is no need to distinguish migration and dispersal as a process. Micromigration usually has no direction or it may occur in many directions. Interpopulation migration can have a direction searching for a new area (Naumov, 1969), or it can have no or many directions (e. g. sparrows in autumn, according to Pinowski, 1965).

In this paper I will call dispersion the result of migration, that is, distribution. By contrast, the process of movement in search of new areas, I will call migration. Obviously, the terms migration and dispersion can be used as synonyms. Then the term dispersion will have a double meaning: the process of dispersal movements (migration, as proposed here) and its result, distribution.

Macromigration, that is, leaving the area of the population and settling within the area of another population, has not been described 
for the bank vole so far. It is obvious that for longer periods of time macromigration is a logical postulate. The island we have studied on a lake had to be colonized at some time in the past; this was a macromigration - settling in a new habitat. However, there are no literature data on macromigration, therefore I will discuss only micromigration.

I have defined micromigration as the process of movement beyond

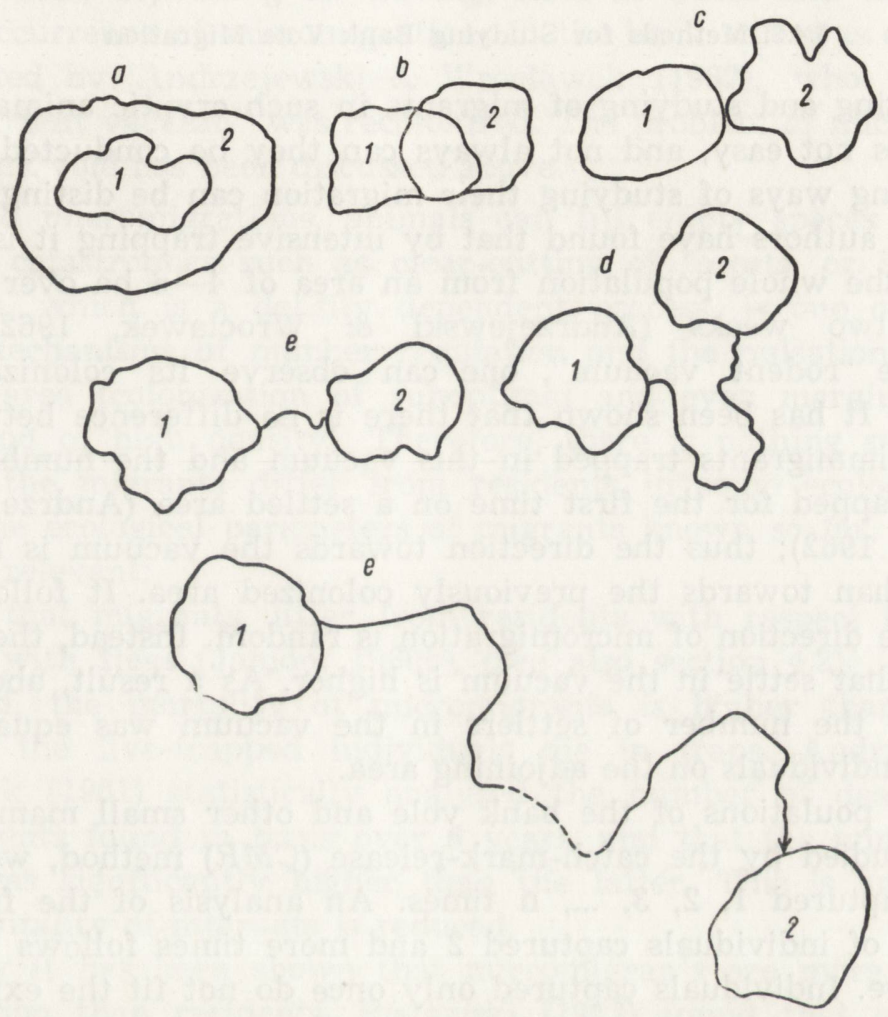

Fg. 6.12. Changes in the area and migration. 1 - original area, $2-$ new area. Explanations see text.

the population area till settlement in a new area (or death). But there is no a clear-cut boundary between the change of the area and migration (Fig. 6.12). The cases $a, b$, and $c$ in Figure 6.12. I will certainly consider as a change in the area without migration, while $e$ is a micromigration. But there is a certain doubt in cases $c$ and $d$. Surely the old area has been left and a new area has been colonized. But if this new area was within an hour or a day, is this still a migration? This question cannot be answered satisfactorily. Besides, I have no data on the distance of bank vole migrations. These issues will be discussed in more detail in the next subsection. 
To end these preliminary remarks, I wish to emphasize that the tendency to migrate need not be genetically determined. There are many data (Naumov, 1956; Andrzejewski \& Wrocławek, 1962; Petrusewicz \& Andrzejewski, 1962; Andrzejewski, 1963), indicating that a migrating individual become settled and a settled individual became a migrant.

\subsubsection{Methods for Studying Bank Vole Migration}

Recognizing and studying of migrants in such cryptic animals as the bank vole is not easy, and not always can they be conducted directly. The following ways of studying their migration can be distinguished:

1. Many authors have found that by intensive trapping it is possible to remove the whole population from an area of $4-6$ ha over a period of about two weeks (Andrzejewski \& Wrocławek, 1962). Then, creating the "rodent vacuum", one can observe its colonization by immigrants. It has been shown that there is no difference between the number of immigrants trapped in this vacuum and the number of individuals trapped for the first time on a settled area (Andrzejewski \& Wrocławek, 1962); thus the direction towards the vacuum is not more attractive than towards the previously colonized area. It follows from this that the direction of micromigration is random. Instead, the number of rodents that settle in the vacuum is higher. As a result, about three weeks later the number of settlers in the vacuum was equal to the number of individuals on the adjoining area.

2. When poulations of the bank vole and other small mammals are intensely studied by the catch-mark-release (CMR) method, we get individuals captured $1,2,3, \ldots, \mathrm{n}$ times. An analysis of the frequency distribution of individuals captured 2 and more times follows an exponential curve. Individuals captured only once do not fit the exponential curve (Andrzejewski \& Wierzbowska, 1961; Wierzbowska \& Petrusewicz, 1963). They are clearly more abundant. It may be suggested that the individuals trapped 2 and more times are residents. Among the individuals caught only once there are residents with a short time of presence and also migrants, that is, individuals only passing through the study area, so cannot be recaptured (Wierzbowska \& Petrusewicz, 1963).

\subsubsection{Ecological Effects of Micromigration}

Ecological effects of micromigration are important and of different kinds. In the first place one should consider the intrapopulation dispersal: individuals born in any place need not live in this place, but they disperse over the population area. This enhances gene exchange. 
In my view, each species must have passive or active means of dispersal (migration and micromigration). The ability to disperse is a necessary condition for permanent existence of each population. Even sessile organisms must have a possibility of dispersal. This is clearly shown in the study on periphyton (Pieczynska, 1964). Periphytic organisms, are by definition, sessile. Nevertheless, a smaller or larger part of individuals, depending on waving, float in water and then resettle.

The occurrence of micromigrations in the bank vole was conclusively documented by Andrzejewski \& Wrocławek (1962), who found that a 4-ha "rodent vacuum" was recolonized. The problem of micromigration in the bank vole has been discussed above.

Due to micromigrations, animals can fill empty spaces created by different catastrophes such as clear-cutting of forests, or local floods. Migration, which is a density dependent process, is one of the more precise mechanisms of number regulation and the pulsation of the population area (colonization of suboptimal and even marginal habitats in a period of high density). Therefore, there is nothing surprising in the fact the migrants differ from residents in some ecological traits. Among the ecological parameters of migrants known so far, the following seem relevant:

First, that migrants differ from residents with respect to their infestation with fleas (Janion, 1960b), (see also section 4.2).

Second, the mortality of micromigrants is higher than residents. Some of the live-trapped individuals die in traps. Andrzejewski \& Wrocławek (1961) statistically analysed the number of dead migrants and residents found in traps over 6 years, and that the number of the former was significantly higher than the latter. This is an indication that the vitality of migrants is reduced.

Finally it has been shown that micromigrants are more vulnerable to predation than residents. Pielowski (1962) found that most of the bank voles recorded in the diet of vipers were migrants (see section 3.3).

The increased mortality of migrants suggests that immigration as expressed by numbers entering an area - should be lower than emigration i.e., numbers leaving the area. Although this has not been cmpirically confirmed, it appears to be a logical consequence of the increased mortality of migrants as compared with residents. Thus, not all emigrants will have time to become residents, some of them wiil die during migration. As a result, the number of immigrants will be lower than emigrants, especially if one considers a sufficiently large area to exclude immigration into an particularly suitable area.

To some degree it is possible to determine the number of immigrants: 
(Fig. 6.13), however, it is unable to determine the number of emigrants. Using the calendar of captures one can estimate the number of individuals disapearing from the study area. It is not known, however, how many of them died and how many emigrated. For this reason the number of individuals that disappeared is often called elimination (mortality),

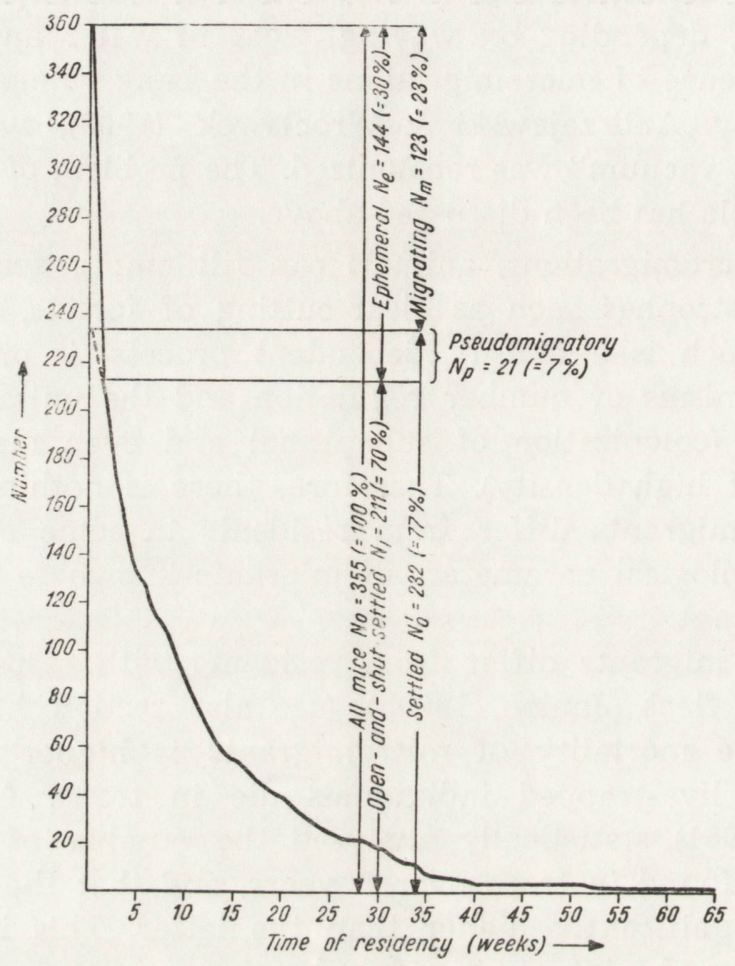

Fig. 6.13. Distribution of length of residency of at least $t$ weeks in a population of mice in the domestic part of the building and its division into ecological categories (from Wierzbowska \& Petrusewicz, 1963).

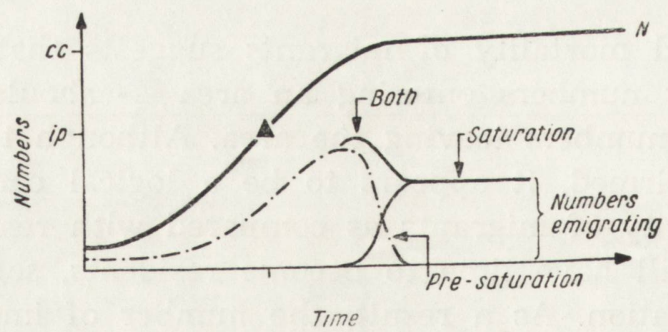

Fig. 6.14. Relation between changes in numbers of a population and both saturation and pre-saturation types of emigration, cc - carrying capacity, ip - stands for inflection point (after Lidicker, 1975). 
though some of them could emigrate. A statement is justified for the study area ("an individual disappeared from this area") but the extrapolation of study area parameters to the whole population can be misleading. Some individuals that disappeared from the study area (10.0 ha, 1.7 ha, 2 ha, 4 ha, 6 ha) could establish a home range in another part of the same population.

Macromigration has a much greater influence on population numbers. This is a loss from the population. The size of macromigration for most species cannot be estimated, thus mortality and macromigration are frequently combined and called gross mortality. When macromigration occurs, it can account for a large part of elimination and, together with mortality, determine population numbers.

Lidicker (1975) distinguished pre-saturation dispersal (migration) and saturation dispersal. This seems an important distinction, and the difference in ecological consequences deduced by Lidicker is convincing (Fig. 6.14). Among more important ecological consequences quoted by Lidicker there are: (1) individuals taking part in pre-saturation emigration are in a good condition; these are not weak animals driven away as is the case during saturation emigration; (2) pre-saturation migration prevents overcrowding in the place of birth. In the bank vole, this migration begins in spring, thus long before peak numbers are reached (see above).

In many studies carried out at the Institute of Ecology PAS, particularly in papers by Andrzejewski (1963) and Kozakiewicz (in litt.), it hat been found that:

- micromigration in the bank vole occurs throughout the year (thus there is also a pre-saturation migration);

- it differs in intensity depending on the population density (saturation migration); since the highest population densities occur in autumn (September-October), the largest migration is observed at that times;

- migrants consist largely of 4-6 week old animals (Kozakiewicz, 1976);

- the body weight of migrants is lower than residents of the same age classes (Kozakiewicz, in litt.); this can be explained by their being driven away by stronger animals (saturation migration), or by the deterioration of their condition during migration;

- the mortality of migrants is higher (Andrzejewski \& Wrocławek, 1961), and they are more vulnerable to predation (Pielowski, 1962). It is thus clear that migrations have important effects of different kinds on population functioning. 